\title{
Angiographic study of digital arteries in workers exposed to vinyl chloride
}

\author{
P FAlAPPA, ${ }^{1}$ N MAGNAVITA, ${ }^{2}$ A BERGAMASCHI, ${ }^{2}$ AND N COLAVITA ${ }^{1}$ \\ From the Istituto di Radiologia dell'Università Cattolica del $S$ Cuore, ${ }^{1}$ and the Istituto di Medicina del \\ Lavoro dell'Università Cattolica del S Cuore, ${ }^{2}$ Roma, Italy
}

\begin{abstract}
Five patients exposed to vinyl chloride were studied by hand angiography and other non-invasive methods, including photoplethysmography, reography, and thermography. Raynaud's phenomenon was present in all five subjects, while acro-osteolysis affected only one. Organic vascular lesions, such as narrowing, segmentary occlusions of digital arteries and bridge collaterals, were found in angiographic studies. Only one patient did not show clear segmentary occlusions, but his vessels were crooked and diffusely narrowed. Angiographic results appear to correlate well with the changes shown by non-invasive techniques.
\end{abstract}

Vinyl chloride causes a complex syndrome, which may include typical Raynaud's phenomenon. The impairment of vascular system function in vinyl chloride disease has been studied in a small group of subjects by means of plethysmography, ${ }^{1}$ thermography, ${ }^{2}$ or angiography. ${ }^{34}$

We were unable to find any published study of all these vascular parameters in the same group of patients.

\section{Materials and methods}

Of 30 workers having vinyl chloride disease, five who complained of severe Raynaud's phenomenon were selected for detailed study. The mean age was 46 years (range 31-56); mean working age was 12.6 years (range 5-22). Three worked in a vinyl chloridepolyvinyl chloride polymerisation factory as autoclave cleaners; the other two worked inside polyvinyl resin silos (bunker workers) in the same factory.

The severity of their Raynaud's phenomenon was evaluated by a traumatic vasospastic disease index ${ }^{5}$ : in all cases the score ranged from 7 to 10 (that is the highest possible score). All the patients showed pseudoclubbing of the fingers, minimal skin changes, hyperidrosis, and paresthesiae. Only one subject had bilateral acro-osteolysis of the index finger; he also had scleroderma-like skin changes.

Each patient underwent digital photoplethysmography, ${ }^{6}$ repeated after cold testing ${ }^{7}$ antebrachial and digital reography, ${ }^{8}$ static and dynamic hand

Received 7 November 1980

Accepted 5 June 1981 thermography, ${ }^{9}$ and angiography.

Hand angiograms were performed during general anaesthesia. Thirty $\mathrm{ml}$ of iodide contrast medium (Urografin $76 \%$ ) were injected, at $6 \mathrm{ml} / \mathrm{s}$, in the brachial artery on each side; two $x$-ray films a second for the first five seconds, and one $x$-ray film a second for the next three seconds were obtained.

A short, deep general anaesthesia ${ }^{10}$ was necessary to complete filling of the digital arteries. We used halothane, a vasodilator anaesthetic, to eliminate painful vasospasm after contrast medium injection ${ }^{11}$; such arterial spasms may mask underlying occlusive disease in patients with Raynaud's phenomenon when the examination is performed under local anaesthesia. ${ }^{12}$ In only one patient was the arteriogram performed firstly under local anaesthesia and secondly under general anaesthesia.

All the investigations were carried out in a thermostatically controlled room $\left(21^{\circ} \mathrm{C}\right)$.

\section{Results}

In the forearms the amplitude of the reogram was reduced in two cases in the basal state; some morphological changes of the descending segment of the sphigmic wave suggested basal vasospasm.

At the fingers during rest four cases showed spontaneous changes of the vascular tone; curves with a wide base and hyperdicrotism, or flattened curves with quickly ascending pulse segment and flatly continuing descending segment, with fairly regular, small waves (saw-waves).

Photoplethysmography showed appreciably flattened curves, with quickly ascending and slowly 169 
descending pulse segments, indicative of a constriction in the arterial system, or "integrated" shape of pulse curves, rounded toward the top, with no dicrotic wave, that indicate the presence of occlusions in the smaller arterial trunks, which are compensated through large-calibre collaterals.

Cold testing evidenced alterations of vascular reactivity ("silent" curves, subsequent appearing of integrated pulse, late pulse recovery).

In all cases thermography showed a non-homogeneous distribution of the longitudinal thermal gradient (LTG), and in several cases abnormal thermographic patterns, ranging in basal conditions from slight hypothermia to clear thermic amputation of some fingers. After cold testing, symmetric amputation affected all the hand up to the metacarpus.

In association with the above findings we found, by arteriography, a generalised narrowing, ranging from scattered stenosis of the vascular lumina in "arteriae digitales propriae," to their complete occlusion. We did not find reduction in size or absence of filling of the palmar arches. ${ }^{4}$ Only in one patient (fig 1) were we unable to observe an obstructive arterial disease; however, the common and arteriae digitales propriae were particularly crooked and irregularly narrowed. A variable degree of crooking was observed also in the remaining cases (figs 2 and 3).

In four subjects we observed complete segmental occlusion of arteriae digitales propriae, with distal revascularisation by means of bridge collaterals.

The development of numerous collaterals and vascular bridges may often determine zones of pseudohypervascularity.

\section{Discussion}

Conventional hand angiography and its variations such as pharmaco and cryodynamic angiography, have been widely used in diagnosing Raynaud's syndrome, both systemic ${ }^{12-14}$ or occupational. ${ }^{3}$ 415-17

Interpretation of the angiograms often proves difficult, since many arteries do not conform to a single anatomical pattern. ${ }^{18} 19$ Moreover, most of the cases reported have been studied by different methods and techniques. ${ }^{12} 1420$

According to published reports it is not possible to attribute any definite pathological importance to variations in the big vessels or palmar arches in respect of diameter or arrangement.

In the lone case we examined under local anaesthesia we observed a very poor arteriogram. We have considered the evidence of filiform vessels and the complete absence of filling of all the arteries that stream out of the palmar arches in angiograms performed without anaesthesia as a physiological or paraphysiological response to contrast medium injection; the degree of correlation with the severity of the Raynaud's phenomenon is poor. We must remember, however, that the early symptoms of Raynaud's phenomenon are vascular hypertonia and
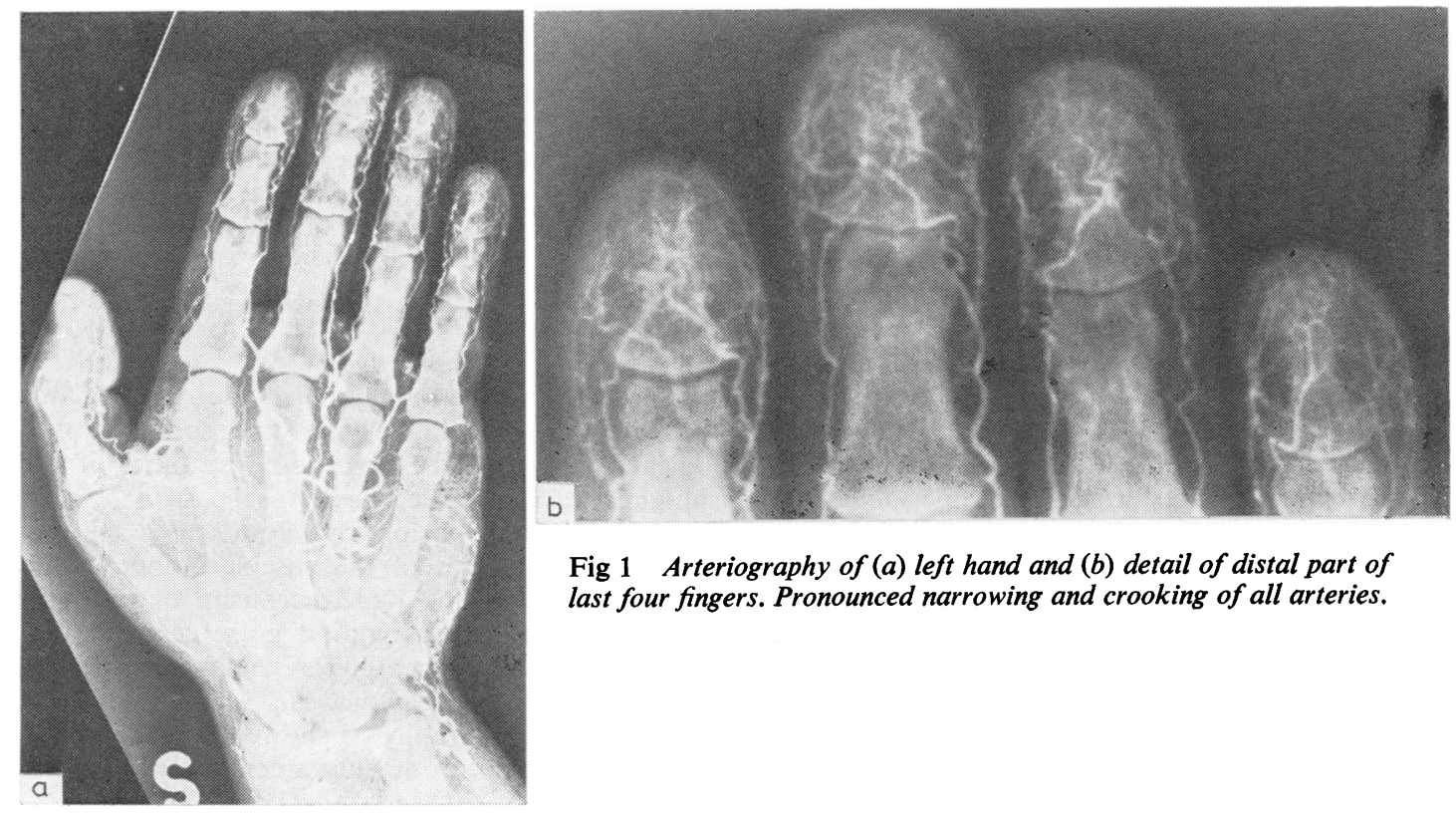

Fig 1 Arteriography of (a) left hand and (b) detail of distal part of last four fingers. Pronounced narrowing and crooking of all arteries. 


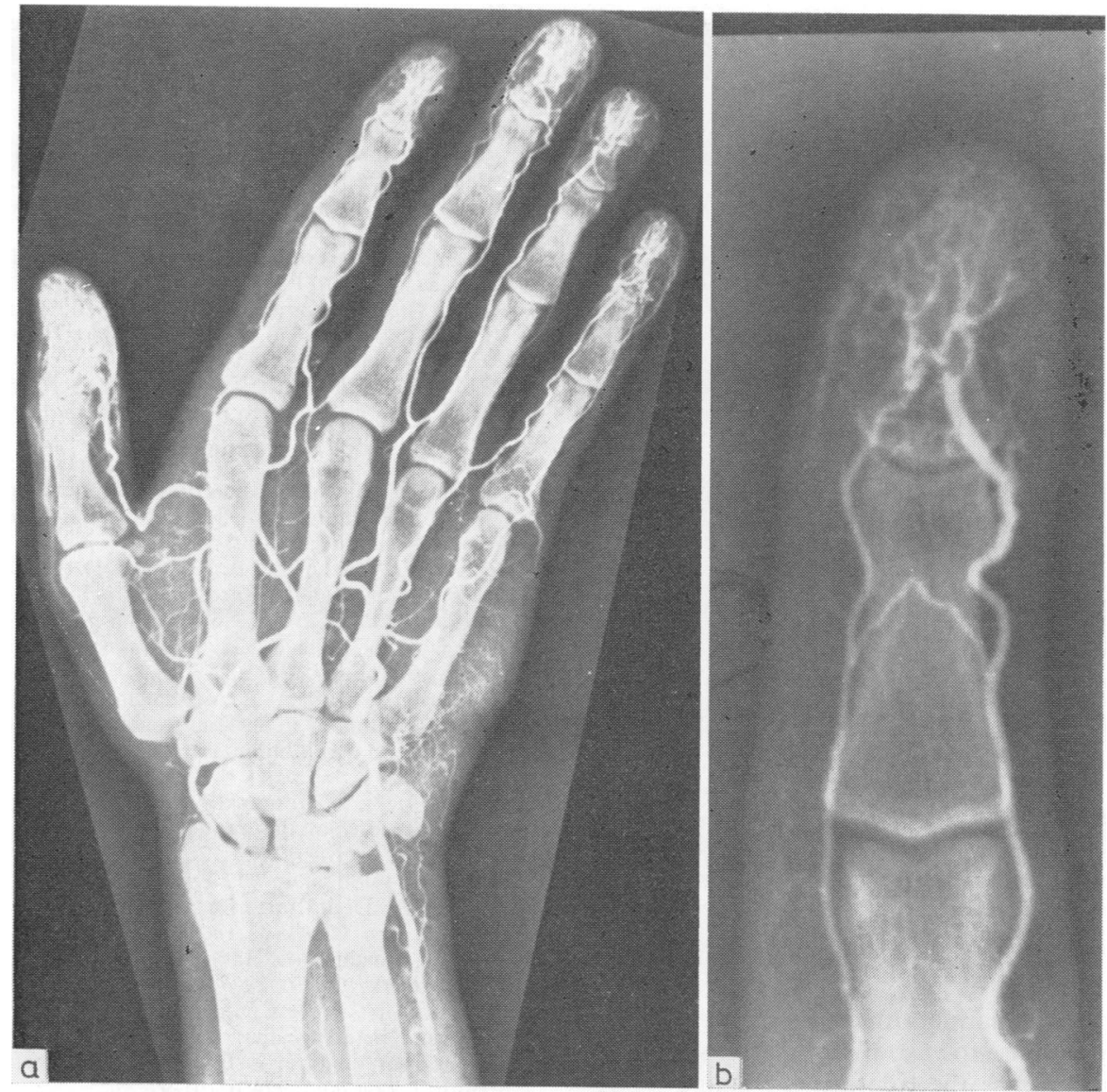

Fig 2 Arteriography of (a) left hand and (b) with detail of second finger. A proper digital artery of fourth finger is extremely narrowed. In the second finger, after a dilated and crooked segment, artery is clearly interrupted.

hyperreactivity with vasospasm precipitated by many stress factors (cold, noise, pain, and so on).

We confirm the signs of organic obstructive disease of the little arteries in subjects affected by vinyl chloride disease - already reported by Lange $\mathrm{et} \mathrm{al}^{3}$ and corresponding to histopathological lesions shown by skin biopsy to consist of uneven endothelial thickening, and thickening of the media of dermal arterioles, with inflammatory infiltrates, predominantly perivascular (lymphocytesi, few histiocytes). ${ }^{4}$

\section{Conclusions}

We found a substantial correlation between the results obtained by non-invasive methods and by angiography. We cannot, however, exclude the possibility that a study of a larger number of patients may show discrepancies among reo-plethysmographic and thermographic tests and angio- graphy. In fact, many patients with classical occlusive disease can be found to have plethysmograms in the normal range, because the plethysmogram tends toward normality when the arteries are able to deliver a substantial amount of blood to the distal phalanges. ${ }^{13}$ For this reason, plethysmography may underestimate the anatomical extent of disease. On the other hand, some anatomical alterations angiographically shown in the presence of Raynaud's disease may be lacking haemodynamic value. ${ }^{21}$

Therefore, we consider angiography to be a useful adjunct to the diagnosis of vinyl chloride disease. It may show organic vascular lesions before the appearance of lytic bone lesions, and may allow early diagnosis; it may discriminate between organic and spastic lesions, and thus be a good indicator of prognosis ${ }^{14}$; it may be of some value in assessing the prognosis in acro-osteolysis, because subjects with a better collateral vascular system could improve more 


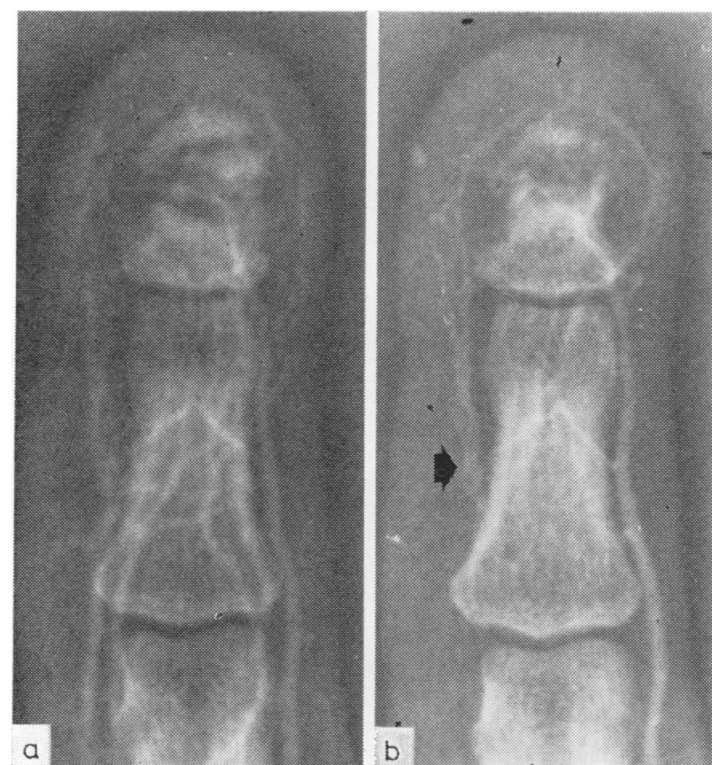

Fig 3 Arteriography of both hands; detail of (a) right finger and (b) second left one. As well as acro-osteolysis of distal phalanges, occlusion of proper digital artery and revascularisation of distal network by bridge collaterals (arrow), distal arteries appear tortuous, narrowed, and apparently increased in number. Pseudoclubbing is present.

quickly.

Pharmacocryodynamic angiography may help to evaluate the response to vasodilator drugs, so helping to choose and assess the treatment. Finally, angiography may provide documentary evidence of the organic lesions in the peripheral circulation for medicolegal purposes. Angiography must be limited to doubtful cases with sufficient risk exposure and must be performed in hospital.

\section{References}

${ }^{1}$ Suciu I, Prodnan L, Ilea E, Păduraru A, Pascu L. Clinical manifestations in vinyl chloride poisoning. Ann $N Y$ Acad Sci 1975;246:53-69.

${ }^{2}$ Réty J, Lazard P, Berrod J, Schmitt M. Apport de la thermographie infra-rouge au diagnostic et à la surveillance des affections consécutives aux opérations de polymérisation du chlorure de vinyle. Archives des Maladies Professionnelles de Médecine du Travail et de Sécurité Sociale (Paris) 1974;7-8:733-8.
${ }^{3}$ Lange CE, Jühe S, Stein G, Veltman G. Die sogenannte Vinylchlorid-krankheit-eine berufsbedingte Systemsklerose? International Archiv für Arbeitsmedizin 1974; 32:1-32.

${ }^{4}$ Veltman G, Lange CE, Jühe S, Stein G, Bachner U. Clinical manifestations and course of vinyl chloride disease. Ann NY Acad Sci 1975;246:6-17.

${ }^{5}$ Pyykkö I. The prevalence and symptoms of traumatic vasospastic disease among lumberjacks in Finland. Work Environmental Health 1974;11:118-31.

${ }^{6}$ Torrazza PL, Frau P, Fulghesu G, Nissardi GP. L'impiego della fotopletismografia digitale nello studio semeiologico del fenomeno di Raynaud da strumenti vibranti. Folia Med 1967;50:986-1000.

${ }^{7}$ Okada A, Yamashita T, Ideda T. Screening test for Raynaud's phenomenon of occupational origin. Am Ind Hyg Assoc J 1972;33:476-82.

${ }^{8}$ Nissardi GP, Frau P, Torrazza PL, Marraccini L. Sull' impiego della reografia longitudinale degli arti nello studio del fenomeno di Raynaud da strumenti vibranti. Folia Med 1967;50:1001-11.

${ }^{9}$ Acciarri L, Carnevale F, Grazioli D. Studio mediante termografia a raggi infrarossi dell'angiopatia da strumenti vibranti. Med Lav 1977;68:125-34.

${ }^{10}$ Sadove MS, Wallace VE. Halothane. Philadelphia: FA Davis Company. 1962:32-3.

11 Viehweger G, Plötz J. Vergleichende angiographische Untersuchungen in Lokal, Regional und Allgemeinanästhesie an der oberen Extremität. ROEFO 1974;121: 303-10.

12 Kent SJS, Lea Thomas M, Browse NL. The value of arteriography of the hand in the Raynaud's syndrome. $J$ Cardiovasc Surg 1976;17:72-80.

13 Dabich L, Bookstein JJ, Zweifler A, Zarafonetis CJD, Arbor A. Digital arteries in patients with scleroderma. Arch Intern Med 1972;130:708-14.

${ }^{14}$ Rösch J, Porter JM. Hand angiography and Raynaud's syndrome. ROEFO 1977;127:30-7.

${ }^{15}$ Giuliano G, Cavina C, Bartoli V, Dorigo B, Focardi L. Reperti arteriografici nella patologia vascolare da vibrazioni degli arti superiori ("angiopatia da vibrazioni”). Lav Um 1974;6:161-97.

16 James PB, Galloway RW. Brachial arteriography in vibration induced white finger. In: Taylor $\mathrm{W}$, ed. The vibration syndrome. London: Academic Press, 1974:195203.

${ }^{17}$ Koischwitz D, Marsteller HJ, Lackner K, Brecht G, Brecht Th. Veränderungen der Hand- und Fingerarterien bei der Vinylchloridkrankheit. ROEFO 1950;132:62-8.

${ }^{18}$ Edwards EA. Organization of the small arteries of the hand and digits. Am J Surg 1960;6:837-46.

${ }^{19}$ Calenoff L. Angiography of the hand: guidelines for interpretation. Radiology 1972;102:331-5.

${ }^{20}$ Servelle M. Syndrome de Raynaud et artériolite des doigts. III : Étude artériographique. Pathologie vasculaire. Paris: Masson et cie, 1973:214-8.

${ }^{21}$ Nuzzaci G, Giuliano G, Boccuni M, Cupelli V, Arcangeli C. Ricerca emodinamica e rilievi fisiopatologici nell' angiopatia da vibrazioni degli arti superiori. Lav Um $1976 ; 6: 161-73$. 